\title{
Taik-Won Kim, the First Korean Clinical Psychiatrist
}

\author{
Heon-Jeong Lee \\ Department of Psychiatry, Korea University College of Medicine, Seoul, Republic of Korea
}

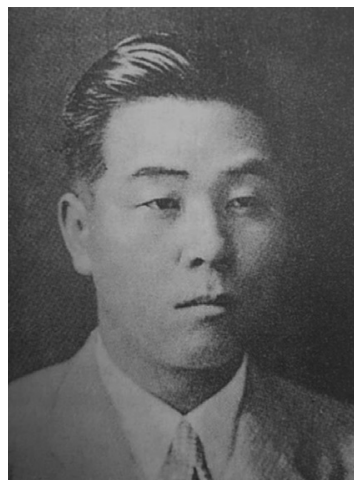

Dr. Taik-Won Kim (circa 1933).
While there is an active debate about who was the first Korean psychiatrist, the answer depends on how we define a psychiatrist. In 1925, the first person to establish a private psychiatric hospital in Seoul began treating psychiatric patients. This person was TaikWon Kim. He was born in Daegu, Korea on July 16, 1898, and this year marks the 120th anniversary of his birth. He only completed elementary school, but he entered Kyungsung Medical College by passing a government exam. After participating in the 3.1 Independence Movement in 1919 while attending Kyungsung Medical College, he was imprisoned for one and a half years by the Japanese imperialist police. He became a doctor after graduating from medical school two years later than his classmates in 1921. Following his graduation from Kyungsung Medical College, he trained at two separate psychiatric institutes: the Japanese National Mental Hospital in Tokyo in 1922 and the psychiatry department of the Peking Union Medical College Hospital in China in 1923. After completing this training, he returned to Korea. In 1925, he opened the first private psychiatric hospital in Korea at Seosomun, Seoul, Korea. ${ }^{1}$

At that time, he had an exceptional reputation as a psychiatrist and operated a hospital equipped with an inpatient room. When Hun-Young Park, who was imprisoned in the case of the Chosun Communist Party in 1927, showed symptoms of mental illness, he was hospitalized at Dr. Kim's Hospital. ${ }^{2}$ However, when Mr. Park recovered from his psychotic symptoms and crossed the Yalu River the following year, he was exiled to the Soviet Union in 1928, and Dr. Kim was subjected

\footnotetext{
$\triangle$ Correspondence: Heon-Jeong Lee, MD, PhD

Department of Psychiatry, Korea University College of Medicine, 73 Inchonro, Seongbuk-gu, Seoul 02841, Republic of Korea

Tel: +82-2-920-6721, Fax: +82-2-929-7679, E-mail: leehjeong@korea.ac.kr

(c) This is an Open Access article distributed under the terms of the Creative Commons Attribution Non-Commercial License (http://creativecommons.org/licenses/bync/4.0) which permits unrestricted non-commercial use, distribution, and reproduction in any medium, provided the original work is properly cited.
}

to suspicion and repression by the Japanese imperialists.

Dr. Kim was a national activist who lived his life for the Korean people and against Japanese oppression. In 1927, the "Emetine poisoning incident" occurred in Youngheung, Hamnam. In this case, the Hygiene Division of the Japanese Police injected emetine without clinical evidence of effectiveness in 105 patients with the Paragonimus westermani lung disease, resulting in five deaths, six severe conditions, and 93 people being intoxicated. However, the governor general and local public officials announced that the victims had died from acute aggravated pneumonia. Local Korean doctors insisted that the patients had been poisoned, and the Dong-A Ilbo reported that there was a public opinion that there was a human experiment to determine whether emetine affects lung disease. Therefore, public opinion was raised in the society, and a truth investigation committee was formed, centering on the Hansung Medical Society. The committee decided to dispatch Dr. Taik-Won Kim and Dr. Seung-Mok Park to investigate the facts. They reported that people died of emetine poisoning. As a result, anti-Japanese movements took place in Yeongheung and Haenam.

Dr. Kim was elected twice as the president of the Hansung Medical Society, which was created in opposition to the "Kyungsung Medical Society," a pro-Japanese Society. He was also devoted to medical education and helped Dr. Rosetta S. Hall with his wife, Dr. Chung-Hee Kil, in 1928 to establish the Chosun Women's Medical Training Institute. ${ }^{3}$ Starting in 1928, Dr. Kim taught psychology and internal medicine as a professor at the Women's Medical Training Institute. After Dr. Rosetta S. Hall's retirement, Dr. Kim became the dean of the Women's Medical Training Institute from 1933 to 1937. This medical training institute is the predecessor of the current Korea University College of Medicine. ${ }^{2}$

In 1939, at the age of 42, Dr. Kim passed away from hepatitis. However, his love for the Korean people through his practice and his pioneering spirit as the first Korean psychiatrist remains in the hearts of all those who remember him. ${ }^{4}$

\section{REFERENCES}

1. Kim SD, Lee HJ. Women's Medical Training Institute Based on the 
Historical Documents. Seoul: Hanrimwon; 2003.

2. Korean Neuropsychiatric Association. 100 Years of Psychiatry in Korea. Seoul: MLcomm.; 2009.

3. Kyungsung Women's Medical Training Institute. Alumni Association
Journal of the Kyungsung Women's Medical Training Institute., Seoul: Hansung Publication; 1934.

4. Kim SD. The Major Achievements of Dr. Kim Taik-Won. Seoul: Hanrimwon; 2009. 